\title{
Redes sociales y medios de comunicación: desafíos legales
}

\author{
Por Antonia Salvador-Benítez y María-Estrella Gutiérrez-David
}

\begin{abstract}
Resumen: Todo parece indicar que para sobrevivir en un entorno virtual los mass media necesitarán incorporar algunos de los principios operativos específicos de los social media. Se explica cómo los medios tradicionales están implementando aplicaciones 2.0, incorporando a su know how nuevas formas de interacción basadas en la participación colaborativa y en los contenidos generados por el propio usuario. Algunos medios españoles, como Elpais.com, en prensa online, y RTVE.es, en el sector audiovisual, representan diferentes estrategias donde los usuarios comparten ideas, información, entretenimiento y proyectos. Sin embargo, con el uso de las herramientas 2.0, usuarios y medios se enfrentan a potenciales riesgos legales relacionados con la propiedad intelectual, los datos personales, la vida privada, el honor y el derecho a la propia imagen.
\end{abstract}

Palabras clave: Redes Sociales, Web 2.0, Social media, Medios de comunicación, Gestión de contenidos, Contenidos generados por el usuario, Archivos audiovisuales, Datos personales, Vida privada, Propiedad intelectual, Creative commons.

Title: Social networks and mass media: legal challenges

Abstract: All trends seem to indicate that, to survive in a virtual environment, mass media need to incorporate some operational principles specific to the social media. This paper focusses on how the traditional Media are implementing 2.0 tools, incorporating to their know-how a new way of interaction with users based on collaborative participation and users-generated content. Some Spanish media, such as Elpais. com for online press and RTVE.es for the audiovisual sector, represent different strategies where users are connected with each other; they share ideas, information, entertainment and projects. However, when using 2.0 tools users and media should know they are facing potential legal risks, especially related to intellectual property, personal data protection, privacy, reputation and right to publicity.

Keywords: Social networks, Web 2.0, Social media, Mass media, Content management, User generated content, Audiovisual archives, Personal data, Privacy, Intellectual property, Creative commons.

Salvador-Benítez, Antonia; Gutiérrez-David, María-Estrella. "Redes sociales, 2.0 y medios de comunicación: desafíos legales". El profesional de la información, 2010, noviembre-diciembre, v. 19, n. 6, pp. 667-674.

DOI: 10.3145/epi.2010.nov.14

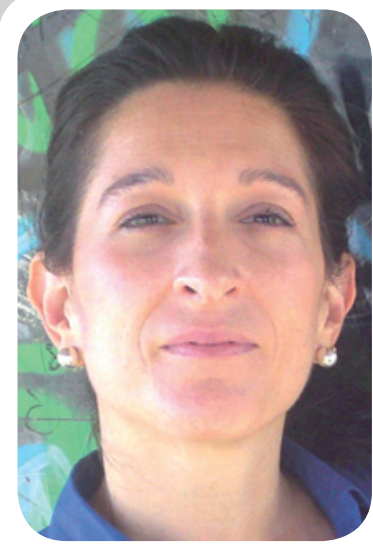

Antonia Salvador-Benítez es doctora en documentación por la Universidad de Granada y profesora del Departamento de Biblioteconomía y Documentación en la Universidad Complutense de Madrid. Sus líneas de investigación se centran en la documentación en medios de comunicación gestión de archivos, tratamiento y preservación digital, temas sobre los que ha publicado el libro "Archivos fotográficos. Pautas para su integración digital" (2006) y diversos artículos. Entre sus trabajos más recientes está el artículo "Políticas de salvaguardia y acceso en los archivos audiovisuales de televisión. Marco jurídico y nuevos servicios interactivos en la televisión digital" (2010) y el capítulo de libro "La técnica legislativa en las normas dirigidas al ámbito audiovisual español, factor de transparencia" (2010). Ha participado en proyectos financiados por instituciones nacionales y por la Comisión Europea.

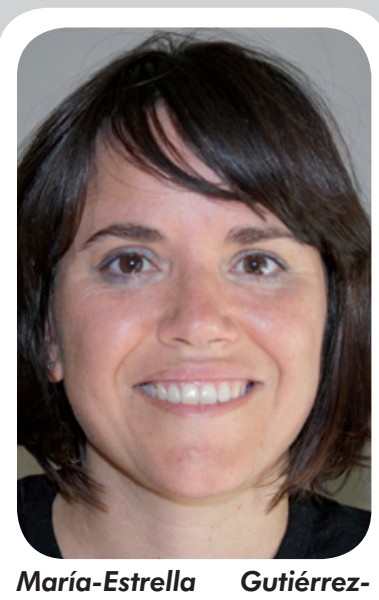

María-Estrella Gutiérrezcho de la información y de las telecomunicaciones en la Universidad Carlos III de Madrid y en el CES Felipe II, adscrito a la Universidad Complutense de Madrid, donde también imparte la materia derechos de autor y de la propiedad intelectual. Es miembro del grupo de investigación TrustCM "Cultura de la legalidad, transparencia, confianza y responsabilidad", dentro del programa Actividades de I+D entre grupos de investigación de la Comunidad de Madrid en socieconomía, humanidades y derecho. Ha publicado los libros "Justicia y medios de comunicación. Claves para la buena praxis de los derechos informativos" (2007) y "La transparencia en el sector audiovisual. Comentarios a la normativa europea y comunitaria" (2008); capítulos de libros y artículos. Asimismo, ha dado conferencias en el extranjero, tal como "Tax incentives to foster national films: an exception to the State aids' prohibition" (Düsseldorf, 2010).

\section{Introducción}

LOS MEDIOS DE COMUNICACIÓN son conscientes de la importancia de su presencia en internet. Los cambios que se están produciendo en los hábitos de consumo de información y sus posibles implicaciones socioculturales hacen que la distribución online no sea suficiente. El reto está en definir y estructurar una identidad digital para ganar adeptos y consolidar una audiencia fiel off-online.

Este nuevo marco exige que los agentes del sector conozcan las po- 
sibilidades que las redes sociales y las aplicaciones 2.0 ofrecen para la elaboración de nuevos productos y servicios así como la adaptación a nuevas necesidades comunicativas en relación con la participación abierta y la gestión de contenidos. Pero con la web 2.0 están surgiendo nuevos desafíos legales que conviene identificar, como la protección de datos personales y los derechos de propiedad intelectual. La literatura existente no ha hecho más que empezar y, como ya es habitual desde que apareciera internet, el derecho va muy por detrás de la realidad.

En el presente trabajo se exponen los principales antecedentes que definen el fenómeno social media así como un breve análisis de la presencia de los medios de comunicación en las redes sociales, la incorporación de aplicaciones 2.0 como nuevo modelo de interacción con el usuario y la participación colaborativa. Se comentan algunas prácticas seguidas por los medios de comunicación tomando como referencia Elpais.com para la prensa en línea y RTVE.es en el sector audiovisual. Finalmente se plantean los principales desafíos legales en lo referido a la gestión de contenidos y protección de datos personales.

\section{El fenómeno social media: ¿nuevo paradigma para los mass media?}

Josh Bernoff acuña el término groundswell $^{1}$ (mar de fondo) para referirse al cambio social que ha provocado el uso generalizado de las nuevas tecnologías en internet por parte de la sociedad para comunicarse entre sí y con las empresas de una forma fácil y barata hasta ahora desconocida. En sentido metafórico, el término representa la ola de democratización social que ha universalizado el uso de internet. Esta combinación de tecnología y el uso que le dan las personas recibe el nombre de social media (Angioletti, 2009).
Kaplan y Haenlein (2010, p. 61) definen social media como "conjunto de aplicaciones basadas en internet, edificadas sobre los fundamentos ideológicos y tecnológicos de la web 2.0, que permiten la creación y el intercambio de contenidos generados por el usuario". Los autores señalan que junto a los blogs y a los microblogs (Twitter), también los proyectos colaborativos (Wikipedia), las redes sociales (Facebook), las comunidades de contenidos (YouTube), los mundos de juegos virtuales (World of Warcraft) y los mundos virtuales sociales (Second life) son parte de los social media.

Aunque los entornos colaborativos surgen inicialmente en los ámbitos educativos y personales, en los últimos años han empezado a formar parte de las estrategias empresariales, donde la transformación ha incorporado una serie de cambios en el modelo de comunicación con los empleados, los usuarios y el mercado así como en el modo de trabajar. Éste se puede hacer más eficiente dinamizando comunidades y grupos de trabajo y expandiendo el uso de los social media. El objetivo es promover la transformación de la empresa en un momento de cambio como el actual y para ello es fundamental la colaboración.

El resultado es que se han generalizado nuevas formas de participación como la denominada e-participación (Sæbø; Rose; Nyvang, 2009) en el entorno político; la $e$ administración (eGovernment) para las gestiones y comunicaciones con los organismos de la administración pública o el media activism en el ámbito de la sociedad civil, para movilizar a la opinión pública en asuntos de relevancia mediante uso de las aplicaciones 2.0 (Rodan; Balnaves, 2009).

Los medios de comunicación tradicionales deben incorporar a su know-how buena parte del plantea- miento de los social media tanto en la forma de trabajar (colaboración, participación, retroalimentación, democratización) como en los instrumentos empleados (contenidos generados por el usuario, comunidades y herramientas 2.0).

\section{"Los medios de comunicación deben incorporar el planteamiento de los social media en la forma de trabajar"}

El barómetro del CIS correspondiente a septiembre de 2009 pone de manifiesto la intensa utilización de herramientas 2.0 en las principales actividades que los españoles realizan en internet. Los datos constatan que un $42,7 \%$ de los ciudadanos utiliza foros, chats o servicios de mensajería instantánea como el Messenger; un 31,5\% tiene un perfil creado en redes sociales como Facebook, Tuenti o Myspace y un nada despreciable 14,3\% mantiene su propio blog o sitio web y cuelga material gráfico o audiovisual (fotos, vídeos) online. Las actividades más generalizadas son la búsqueda de información $(91,2 \%)$ y la descarga de contenidos audiovisuales $(42,2 \%)$, datos importantes si tenemos en cuenta que, en muchos casos, también se realizan mediante aplicaciones 2.0 como la Wikipedia y YouTube ${ }^{2}$.

Los medios de comunicación no han permanecido ajenos al fenómeno social media y sus instrumentos básicos, la web 2.0 y el user generated content. Cada vez son más conscientes de que "proporcionar información ya no es suficiente; la información es la materia prima, la commodity; la comunicación es el servicio" (Lara, 2008). Por esta razón el reto estriba en captar nuevos 
públicos e introducir a sus usuarios en las redes sociales. Lara (2008) apunta las principales razones del cambio de estrategia:

- Es una nueva forma de reconectar con la sociedad y superar la crisis de autoridad, mediación y credibilidad en la que están sumergidos los medios de comunicación.

- El perfil del consumidor de noticias en medios tradicionales envejece, lo que obliga a los medios a crear nuevos entornos para acercarse a un público más joven y conectar con sus necesidades de información, comunicación y entretenimiento. Se abre así un nuevo mercado a explorar para atrapar y segmentar grupos de población que puedan ser de interés comercial.

\section{Presencia de los medios de comunicación en las redes sociales}

Todos los medios de comunicación tienen que competir con internet, o integrarlo en la estrategia empresarial y de programación ${ }^{3}$. Esto justifica que las páginas de $\mathrm{Fa}$ cebook y Twitter se hayan convertido en una buena forma de captar audiencia para los diarios y emisoras tradicionales. Prueba de ello son los 1,4 millones de personas que siguen a las principales cadenas de televisión, radios y periódicos en las redes sociales. Así lo revela el Informe 2010 medios de comunicación españoles en las redes sociales, elaborado por el Gabinete de Análisis Demoscópico (GAD) que señala que 720.000 personas siguen algún medio de comunicación en Facebook, 665.000 lo hacen en Twitter, y 92.000 en YouTube ${ }^{4}$.

La actual variedad de redes sociales permite que los medios de comunicación hayan acudido a la red que más se ajusta al perfil de su audiencia. Así, las cadenas de televisión se han posicionado principalmente en la plataforma de vídeos online YouTube, donde tienen casi 90.000 suscriptores fijos, con cientos de miles de descargas de diarias. Las radios han encontrado en la red social Facebook la mejor aliada para crear comunidades de miles de personas que comparten su afición al mismo programa de radio, un total de 350.000 fans según datos del informe. En cuanto a la prensa, es la mejor posicionada en la web de microblogging Twitter, donde las principales cabeceras españolas cuentan con más de medio millón de seguidores. El motivo de este éxito entre los periódicos, a juicio de $G A D$, es que esta red permite a sus versiones digitales abrirse a la retransmisión en directo realizada por los ciudadanos.

\section{"Para los medios de comunicación tradicionales Facebook y Twitter son una buena forma de captar audiencia"}

Los datos no dejan margen de duda, los medios de comunicación quieren fortalecer su presencia en internet, pero para planificar una buena campaña de marketing en este nuevo escenario, va a ser imprescindible la figura de un gestor de redes sociales o "community manager". Jennifer Preston, que trabaja como "social media editor" en The New York times, opina que la gestión de redes sociales es una labor periodística esencial, ya que son muy útiles para encontrar fuentes, seguir y explorar tendencias, captar ideas e investigar (JiménezCano, 2010).

De esta forma, los mass media tradicionales constatan cómo, cada vez más, necesitan "más adquisiciones e inversiones online" (SanMillán; Medrano; Blanco, 2008, p. 356), y cómo, también cada vez más, necesitan de la filosofía subyacente en los social media para "revitalizar sus propios negocios" (Bäck; Vainikainen, 2007, p. 372). Deberían tener presente que proyectos colaborativos como la Wikipedia comienzan a ser la principal fuente de información de muchos usuarios (Kaplan; Haenlein, 2010, p. 62).

La crisis económica -la propia del sector y la general- posiblemente obligue a los medios a realizar cambios en sus planteamientos tradicionales, incorporando en clave colaborativa los tres pilares de los social media: contenidos generados por el usuario, comunidades y la web 2.0 (Ahlqvist et al., 2008, p. 13). Y buena parte de sus principios y su filosofía: colaboración, participación, retroalimentación, transparencia y democratización.

\section{Tecnologías $2.0 \mathrm{y}$ participación del usuario}

El periódico español pionero en abrir un espacio informativo de estas características a los lectores es Elpaís.com, que en 2007 puso en marcha Yo, periodista, una iniciativa para que los ciudadanos se conviertan en informadores enviando textos, fotografías o vídeos, tanto desde internet como mediante un mensaje multimedia de móvil. Además ofrece a los lectores la posibilidad de comentar las noticias, una práctica ya muy extendida en los medios online.

\section{http://www.elpais.com/yoperiodista}

Junto a esta primera iniciativa lanza La comunidad, un espacio donde los usuarios pueden crear y mantener de forma gratuita su página personal en formato blog, proporcionándoles un lugar donde escribir, colgar sus fotos, vídeos o audios y compartirlos con otros internautas, creando comunidades de amigos según sus temas de interés. El único límite está en escribir con respeto y no usurpar la identidad de otras personas.

http://lacomunidad.elpais.com 


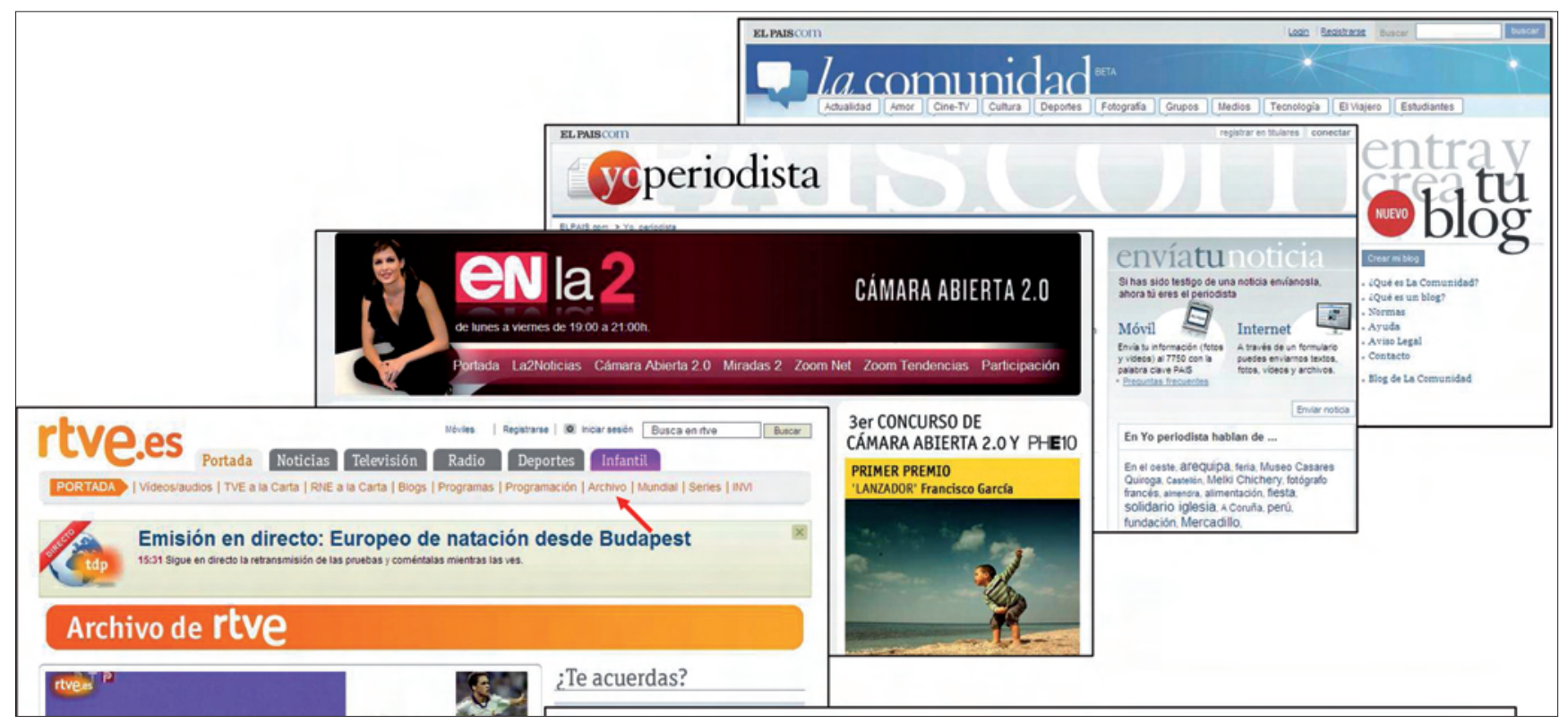

Figura 1. Servicios y aplicaciones 2.0

En cuanto al medio televisivo, la fragmentación de pantallas y audiencias en distintos micromedios (blogs, redes sociales, wikis...) también está alterando a gran velocidad el sector. En este contexto disperso y plural, las televisiones no han querido quedarse atrás y se han lanzado a crear espacios de referencia personal y comunitaria, donde la audiencia pueda interactuar con ellas y con otros usuarios. Sirva de muestra el programa Cámara abierta 2.0 de La 2 de Televisión española donde los contenidos los proporcionan los propios televidentes, que graban en vídeo su propia historia. Además, la web se convierte en una extensión del programa, una vía de retroalimentación y una plataforma de difusión e interacción con otros usuarios.

http://www.rtve.es/noticias/enla2/ camara-abierta

La participación del usuario no tiene marcha atrás. Preston piensa que informar en tiempo real es uno de los grandes retos de la prensa el mejor exponente de este uso fue durante los terremotos de Haití y Chile- y para eso los lectores son imprescindibles. Sin embargo indica que el servicio al usuario no debe estar reñido con el rigor, "la selección de estos contenidos es la clave" pero es muy importante "re- conocer qué nos piden, darles crédito, dejarles ser parte de un medio que también es suyo" (JiménezCano, 2010).

En este sentido, Yo, periodista detalla en las condiciones de participación y uso de este servicio que las informaciones han de ser veraces, tienen que esta redactadas de forma clara y sencilla y no pueden atentar contra el honor de terceras personas, requisitos que son vigilados y reforzados por un equipo de periodistas.

\section{Datos personales y privacidad}

Las aplicaciones 2.0 suelen requerir el registro y la cesión de ciertos datos personales (nombre, teléfono, dirección de contacto). El tratamiento de estos datos (recabamiento, conservación, rectificación, cancelación o cesión a terceros) suele estar incluido en la sección "política de privacidad" ubicada en la página principal de la web, sin perjuicio de que en algunos casos, el usuario deba rellenar formularios concretos para el acceso a determinados servicios y de que éstos dispongan de una política de privacidad adicional.

Según el barómetro del CIS de septiembre de 2009 , casi un $57 \%$ de los usuarios de internet considera que la seguridad en la privacidad de los datos es baja o muy baja y un $70 \%$ cree que el uso de internet favorece la intromisión en la vida privada de las personas. Abundando en prácticas que implican la utilización de aplicaciones 2.0, alrededor de un $76 \%$ valora negativamente en términos de confianza acciones como colgar fotos o vídeos propios o de amigos y familiares; al tiempo que a casi un 50\% le ofrece poca o casi ninguna seguridad la participación en sitios de redes sociales como $\mathrm{Fa}$ cebook o Tuenti. Sin embargo, por contradictorio que parezca y a pesar de esta apariencia de inseguridad y vulnerabilidad que generan internet y las aplicaciones 2.0 , los usuarios no suelen informarse de las políticas de privacidad de los sitios web que visitan (tabla 1).

\begin{tabular}{|l|r|}
\hline $\begin{array}{c}\text { ¿Con qué frecuencia } \\
\text { lee las políticas de } \\
\text { privacidad de los sitios } \\
\text { web que visita? }\end{array}$ & $\%$ \\
\hline Siempre & 4,1 \\
\hline Casi siempre & 7,7 \\
\hline Algunas veces & 21,7 \\
\hline Raramente & 26,2 \\
\hline Nunca & 35,6 \\
\hline No sé cómo hacerlo & 4,0 \\
\hline
\end{tabular}

Tabla 1. Fuente: CIS septiembre 2009 
La conclusión es clara: una gran mayoría de los internautas desconoce las políticas de privacidad de los sitios que visita y que afectan no sólo al tratamiento de sus datos personales, de su intimidad y vida privada sino, por extensión, a los derechos a la propia imagen e incluso al honor.

\section{"Los usuarios no suelen informarse de las políticas de privacidad de los sitios web que visitan"}

Estos datos hacen tener en cuenta las cuestiones jurídicas que está planteando la utilización de estas aplicaciones. Los sitios de redes sociales, los servicios de alojamiento de vídeos, los blogs, las wikis, los mashups ${ }^{5}$, entre otros, frecuentemente plantean problemas legales con relación a los datos personales, intimidad y vida privada, honor, y propia imagen (Comisión Europea, 2008; Inteco y AEPD, 2009; Hoadley et al., 2010), la seguridad (Ofcom, 2009; Enisa, 2007), la protección de menores (Lusoli; Miltgen, 2008) y los derechos de propiedad intelectual e industrial de terceros (Lehmberg et al., 2008).

\section{Derecho al honor y a la propia imagen}

Por lo general los medios online suelen incluir en sus "avisos legales" o "condiciones de uso" cláusulas de exención de la responsabilidad por las opiniones vertidas "por los usuarios en los foros, chats u otras herramientas de participación". Esto es importante pues, si bien la Ley de servicios de la sociedad de la información no impone un deber de supervisión a los proveedores de servicios en internet, la norma sí que prevé la existencia de posibles responsabilidades legales de los proveedores por los contenidos ilícitos publicados por terceros ${ }^{6}$. De manera que estos medios podrían ser responsables de los contenidos ilícitos subidos por los usuarios si se demuestra el conocimiento efectivo por parte del medio y la negligencia en su retirada. Tanto La comunidad de Elpais.com, como Cámara abierta 2.0 de RTVE. es se reservan el derecho a eliminar contenidos que atenten contra la intimidad, el honor y/o la imagen de terceros, con carácter discriminatorio o amenazante.

Cabría plantearse si las normas jurídicas sobre limitación de contenidos podrían extenderse a lo que Kaplan y Haenlein (2010, p. 63), en su clasificación de los social media, denominan virtual social worlds (Second life), donde los internautas viven virtualmente de un modo similar al de la vida real, interactuando en un entorno virtual tridimensional, en el que no existen reglas que restrinjan las posibles interacciones, salvo las leyes físicas básicas. En un contexto tal, ¿podrían los usuarios delinquir? (virtualmente, claro está) ¿La solución sería la autorregulación de la industria -como ocurre con el videojuego tradicional- o la adopción de sistemas de verificación de la edad como hacen algunas redes sociales? (ineficaces, por cierto, en la mayoría de los casos).

\section{"Las webs pueden ser responsables de los contenidos subidos por los usuarios"}

\section{Propiedad intelectual}

Una de las cuestiones no siempre aclaradas en las condiciones de uso de los servicios ofrecidos por los medios online es si los contenidos colgados por los usuarios suponen una cesión de los posibles derechos de explotación (reproducción, distribución, comunicación pública o transformación).

Cuando un usuario cuelga fotografías o vídeos elaborados y editados por él mismo, puede tratarse de trabajos originales ${ }^{7}$ por lo que para su autor genera derechos de propiedad intelectual, como la autoría o el respeto a la integridad de la obra, así como posibles derechos de explotación en caso de que decidiese comercializar este material.

Si llevamos la teoría a la práctica para los medios analizados, Elpais.com ofrece un servicio de compra de derechos de reproducción de fotografías, llamado Venta uno@uno. Dispone de un sistema de búsqueda que, atendiendo a distintos criterios, (temas, subtemas, autor) permite al usuario seleccionar las imágenes que desea. Al no existir especificación al respecto en las condiciones generales de uso, la pregunta es obligada: ¿puede Elpaís.com incorporar a su archivo fotográfico en línea las imágenes que suben los usuarios mediante servicios como Yo, periodista, para comercializarlas después? ${ }^{8}$. Este aspecto es importante por dos motivos. En primer lugar, porque la Ley de propiedad intelectual vigente exige la formalización por escrito de cualquier acto de cesión de los derechos de explotación (los morales son irrenunciables) y en las condiciones de uso del servicio nada se indica sobre la cesión de derechos, por lo que a falta de previsión expresa al respecto, cualquier explotación comercial por parte del medio de una obra audiovisual o fotográfica remitida por el usuario requeriría de su consentimiento. En segundo lugar, porque esta clase de servicios no se ofertan al usuario con sujeción a licencias Creative commons $^{9}$ que permitan al medio online la utilización y comercialización de los contenidos generados por el usuario. Más explícitas son las condiciones de participación en el caso de Cámara abierta 2.0, donde se 
establece la "cesión en exclusiva" a favor de RTVE y las condiciones de dicha cesión.

\section{"No siempre está claro si los contenidos colgados por el usuario suponen una cesión de los posibles derechos de explotación"}

\section{Audiovisuales: valor en alza}

La sociedad es absolutamente audiovisual y a ella se adaptan los mensajes y funciones de los medios. En la reconocida confluencia industrial de los nuevos servicios y contenidos multimedia interactivos, los archivos audiovisuales poseen un valor estratégico social y comercial. La existencia de fondos documentales cada vez más importantes, la demanda de contenidos audiovisuales en los mercados relacionados con la comunicación junto al actual interés de la sociedad por recuperar la memoria colectiva mediante imágenes, ha hecho que la documentación de archivo experimente un valor creciente con una demanda que va en aumento.

La expansión de las redes de banda ancha en internet va a permitir conocer la dimensión y el papel clave que tienen y van a tener los archivos -especialmente los gráficos y audiovisuales- en la nueva comunicación multimedia.

Además del indiscutible interés social, cultural e histórico, el valor de un archivo viene determinado no sólo por la calidad de los contenidos conservados sino también por las posibilidades de reutilización presentes y futuras. La prensa primero y las cadenas de televisión después, han demostrado que la conservación de la documentación en sus archivos tiene una justificación económica definida por las posibilidades de comercialización y reutilización, lo que reduce costes de forma considerable $^{10}$. Son numerosos los ejemplos de prensa online que proporcionan el acceso organizado a sus fondos y colecciones como un servicio específico. En muchos casos disponen de un sistema de búsqueda y recuperación de contenidos en diversos formatos. Estas prestaciones que actúan sobre amplias colecciones constituyen uno de los recursos de mayor interés de los medios de comunicación, no sólo desde el punto de vista del usuario final o no especializado, sino también para investigadores y sociólogos y por supuesto, para los usuarios internos y otros servicios relacionados con el sector de la comunicación (Guallar; Abadal, 2009).

\section{"Las redes de banda ancha permiten ampliar la difusión de los archivos audiovisuales"}

En cuanto al sector audiovisual español, aún son escasas las cadenas de televisión que han optado por ofertar este tipo de servicios. La principal iniciativa procede de RTVE como organismo depositario de la producción audiovisual española. Una de las vías de promoción adoptadas para la difusión pública y promoción social de este patrimonio ha sido el sitio web de la corporación. El servicio denominado "archivo" ofrece una selección de imágenes y sonidos de grandes acontecimientos, así como programas de radio y televisión que han marcado una época. El sistema de consulta permite realizar búsquedas por palabra clave $\mathrm{y}$ además dispone de una opción con prestaciones avanzadas donde se pueden especificar las secciones o colecciones en las que se desea buscar, así como los formatos exis- tentes en el archivo (fotografías, audio y texto).

El importante volumen de documentación unido al elevado coste de la digitalización no siempre va a permitir el acceso en línea a la totalidad de los fondos audiovisuales. Por esta razón, se aplica la digitalización selectiva, atendiendo a demandas internas y/o externas de material de archivo. Para implicar y hacer partícipe al usuario en la prestación y mejora de este servicio, y en consonancia con los nuevos modos de interacción, el archivo histórico de Televisión española ha incorporado una sección en la que se pueden solicitar aquellos programas, series o momentos del archivo histórico que se quiere ver, comentarios que se aplican como criterio para rescatar y digitalizar a demanda el fondo documental. Además de una solución para el archivo, estas aplicaciones 2.0 forman parte de esta nueva línea estratégica para crear comunidades de usuarios y fidelizar a la audiencia mediante otras plataformas, especialmente internet.

\section{Recomendaciones}

La renovación y el cambio de estrategia de los mass media en materia de gestión de contenidos exigen un marco legal estable adaptado al nuevo entorno que garantice un adecuado equilibrio entre la protección y el uso de los contenidos. A modo de conclusión, se recoge una serie de recomendaciones.

La política de privacidad y de tratamiento de datos personales, especialmente cuando se oferten servicios que requieran la creación de perfiles de usuario -ya sean del propio medio o mediante las redes sociales en las cuales esté presente- debería ser accesible desde cualquier página web del medio o, en su caso, establecer un enlace directo. Asimismo, se deben seguir las recomendaciones de la Agencia Es- 
pañola de Protección de Datos y de Inteco (2009, pp. 147-158) en esta materia:

- redactar las condiciones de uso y políticas de privacidad con un lenguaje comprensible para el usuario;

- las configuraciones de perfiles han de tener el mayor nivel de privacidad por defecto, teniendo presente que la práctica común seguida por las redes sociales suele ser la contraria;

- puesta a disposición del usuario de herramientas que le otorguen el control absoluto de la información que publica en la red; es decir, medios que limiten la posibilidad de etiquetar a otros usuarios (recibiendo automáticamente una solicitud de aceptación o rechazo);

- implantación de sistemas que faciliten la comprobación de la edad de los usuarios que intenten acceder al servicio, sobre todo cuando se trate de servicios no aptos o no recomendables para menores.

En aquellos servicios en los que el usuario pueda difundir opiniones o contenidos susceptibles de lesionar derechos de terceras personas, especialmente, el honor y la propia imagen, la dignidad y la seguridad, el medio debería reservarse el derecho de eliminar dichos contenidos, no sólo por garantizar los derechos de los afectados, sino también por evitar las posibles responsabilidades legales que pudieran derivarse de su condición de prestador de servicios de la sociedad de la información.

En los medios de comunicación, los contenidos quedan en el ámbito de la legislación sobre el derecho de autor y el derecho contractual. Por consiguiente, las actividades de acceso, difusión y en cierta medida de conservación en el archivo del medio se rigen y se ven limitadas por los imperativos legales de los titulares del material, ya sea foto, texto, audio o vídeo. El cumplimiento de esta obligación no plantea problemas formales cuando se trata de fuentes propias o fuentes externas (agencias, productoras, etc.) donde la titularidad de los derechos está establecida con claridad. Sin embargo, a medida que se extiende el uso de los social media, que se multiplican las posibilidades del interacción del usuario con el medio y que se generaliza la práctica actual de los contenidos generados por los usuarios, más confusa se vuelve la situación a la hora de establecer con certeza la titularidad de los derechos y el uso de los contenidos. La constatada falta de transparencia en esta materia hace imprescindible que los medios de comunicación cuenten con asesoramiento jurídico para sortear las posibles dificultades que puedan surgir.

En las condiciones de uso de los servicios ofertados deberían incluirse menciones explícitas tanto a la originalidad de los contenidos remitidos por el usuario -y por tanto, que éste es titular legítimo de los derechos de propiedad intelectual de los mismos-, como a la cesión de los derechos de explotación. Con respecto a esto último, las licencias Creative commons son una opción a explorar aún por los medios online, en particular las licencias de reconocimiento, que autorizarían al medio el uso comercial del contenido remitido por el usuario siempre que se indique su autoría. En cualquier caso el reconocimiento de la autoría del usuario -derecho moral irrenunciable- debería ser explícito por parte del medio, evitando la ambigüedad de algunas condiciones de uso de ciertos servicios que parecen sugerir lo contrario.

Como gestores indirectos de un servicio público esencial, los medios de comunicación deben contribuir al desarrollo de la sociedad de la información, mediante la utilización de nuevos servicios conexos o interactivos orientados a conciliar la rentabilidad social que debe inspirar su actividad con la necesidad de dirigirse a la más amplia audiencia atendiendo a fines sociales, educativos e integradores. La actual transformación del modelo informativo, unido al espectacular incremento del consumo audiovisual en la Web abre nuevas posibilidades de utilización y rendimiento de los archivos y la documentación audiovisual en la industria cultural. La progresiva digitalización de los archivos audiovisuales se presenta como una ocasión única para facilitar la accesibilidad a los contenidos atendiendo no sólo a criterios de rentabilidad económica sino también desde la conservación y puesta en valor de este patrimonio documental.

Resulta evidente que facilitar la difusión y el acceso a los contenidos de archivo, implica que en el medio existe una clara conciencia del valor cultural, social e histórico de este patrimonio tanto para la empresa como para la sociedad en general y que por tanto, se ha efectuado sobre los fondos una adecuada gestión documental (inventariado, análisis documental, organización, catalogación, etc.) así como una correcta preservación de todos los documentos que forman parte del archivo audiovisual. De acuerdo con López-de-Quintana (2007) también es competencia de los archivos impulsar políticas de digitalización retrospectiva para salvar la "brecha digital" entre los fondos históricos en soportes analógicos y los entornos digitales de producción.

\section{Notas}

1. El artículo de José-Manuel Angioletti (2009) recoge una síntesis de la conferencia "Tapping the groundswell within your company" que Josh Bernoff impartió en junio de 2009 en las sedes de Telefónica.

2. En el trabajo de Angioletti (2009) se presenta un interesante análisis de mercado en función del uso que se hace de los denominados social media.

3. Un estudio de la Asociación Europea de Publicidad Interactiva (EIAA) realizado a principios 
de 2008 revela por primera vez que los jóvenes de entre 16 y 24 años acceden más frecuentemente a internet que a la televisión (destinando un $10 \%$ más de tiempo a aquel medio), y casi la mitad, declara que su consumo de televisión se ha visto reducido como resultado directo del uso de la Red.

4. El informe analiza el empleo que los principales medios de comunicación impresos, digitales y audiovisuales están realizando de las tres redes sociales más extendidas en España para interactuar con sus audiencias. El análisis se realiza sobre una muestra de 47 medios de comunicación clasificados en: medios generalistas de ámbito nacional, medios generalistas de ámbito regional, medios económicos, prensa deportiva, diarios gratuitos de difusión nacional, medios exclusivamente digitales, cadenas de radio convencionales y cadenas de televisión.

http://www.escacc.cat/docroot/escacc/includes/ elements/fitxers/1083/Medios-de-comunicacionen-las-redes.pdf

5. Aplicación web híbrida que permite al usuario utilizar y combinar de forma fácil y creativa los datos que existen en otras aplicaciones y páginas web para crear un nuevo contenido.

6. Los tribunales han ido admitiendo progresivamente esta posibilidad. Para más información, véase la sentencia del Tribunal Supremo de 9 de diciembre de 2009 en el caso Putasgae.com y la Asociación de internautas contra la SGAE.

7. Téngase en cuenta que el Decreto legislativo 1/1996, del texto refundido de la Ley de propiedad intelectual, diferencia entre "obra audiovisual" y "grabación audiovisual" (arts. 86.1 y 120, respectivamente); así como entre "fotografía" y "mera fotografía" (arts. 10.1h y 128, respectivamente). La distinción entre unas y otras se encuentra en el nivel de originalidad (Saiz-García, 2002) presente en las primeras pero no en las segundas, por lo que el nivel de protección legal es distinto.

8. No está muy claro si del "aviso legal" en el que se establecen las condiciones generales de uso puede deducirse que el Elpais.com es cesionario de los derechos de explotación de los contenidos que cuelgan los internautas en sus servicios, a tenor de lo dispuesto en la cláusula $5^{\text {a }}$ : “[...] Ediciones El país por sí o como cesionaria, es propietaria de todos los derechos de propiedad intelectual e industrial de sus páginas webs, así como de los elementos contenidos en ellas (a título enunciativo, imágenes, sonido, audio, vídeo, software o textos; marcas o logotipos, combinaciones de colores, estructura y diseño, selección de materiales usados, programas de ordenador necesarios para su funcionamiento, acceso y uso, etc.), titularidad de Ediciones El país o bien de sus licenciantes [...]"

9. Las Creative commons son una serie de licencias con distinto alcance que permiten a los autores determinar los usos que autorizan a terceros. Las más conocidas son la licencia de reconocimiento (autoriza cualquier uso comercial o no comercial de la obra a terceros, siempre que se indique la autoría) y la licencia no comercial (la explotación de la obra por terceros queda limitada a usos no comerciales).

10. Una referencia práctica de reutilización, promoción y difusión de su archivo histórico es Televisión Española, con la sección iTe acuer- das? integrada en los informativos con motivo de alguna efemérides o conmemoración y el programa 50 años de..., una serie de 15 documentales que abordan la evolución de la sociedad española desde distintos puntos de vista (la familia, las vacaciones, la música, la mujer, etc.) realizados exclusivamente con material de archivo.

\section{Bibliografía citada}

Ahlqvist, Toni; Bäck, Asta; Halonen, Minna; Heinonen, Sirkka. Social media roadmaps. Exploring the futures triggered by social media. VTT Technical Research Centre, Finland, 2008. http://www.vtt.fi/inf/pdf/tiedotteet/2008/T2454. $p d f$

Angioletti, José-Manuel. "El social media en el mundo de la empresa. Sí, es posible". Sociedad de la información. Fundación Telefónica, 4 nov. 2009.

http://sociedadinformacion.fundacion. telefonica.com/DYC/SHI/Articulos_A_Fondo_El_Social_media/seccion $=1188 \&$ idioma $=e s \_E$ S\&id $=2009100116310293 \&$ activo $=4$.do

Bäck, Asta; Vainikainen, Sari. "Enhancing traditional media services utilising lessons learnt from successful social media applications. Case studies and framework". Openness in digital publishing: awareness, discovery and access, Procs. of the 11th Intl conf on electronic publishing, Vienna, 13-15 June 2007, pp. 371-380. http://elpub.scix.net/data/works/att/148_ elpub2007.content.pdf

Enisa. Security issues and recommendations for online social networks. European Network and Information Security Agency. Heraklion, 2007. http://www.enisa.europa.eu/act/res/other areas/social-networks/security-issues-andrecommendations-for-online-social-networks at_download/fullReport

European Commission. Public consultation on online social networking. July 2008.

Guallar, Javier; Abadal, Ernest. "Evaluación de hemerotecas de prensa digital: indicadores y ejemplos de buenas prácticas". El profesional de la información, 2009, v. 18, n. 3, pp. 255-269. http://eprints.rclis.org/16899/1/epi09_guallarabadal_evaluacion_hemerotecas.pdf

Hoadley, Christopher M.; Xu, Heng; Lee, Joey J.; Rosson, Mary Beth. "Privacy as information access and illusory control: the case of the Facebook news feed privacy outcry". Electronic commerce research and applications, Jan.-Febr. 2010, v. 9, n. 1, pp. 50-60

http://faculty.ist.psu.edu/xu/papers/ecra.pdf

Inteco y AEPD. Estudio sobre la privacidad de los datos personales y la seguridad de la información en las redes sociales. Instituto Nacional de Tecnologías de la Comunicación y Agencia Española de Protección de Datos, febrero 2009.

Jiménez-Cano, Rosa. "La gestión de redes sociales, una labor periodística esencial", Elpais. com, 15 mayo 2010.

http://www.elpais.com/articulo/tecnologia/ gestion/redes/sociales/labor/periodistica/ esencial/elpeputec/20100515elpeputec_2/Tes

Kaplan, Andreas M.; Haenlein, Michael. "Users of the world, unite! The challenges and opportunities of social media". Business horizons, 2010 , v. 53 , n. 1 , p. $59-68$.
Lara, Tíscar. "La nueva esfera pública. Los medios de comunicación como redes sociales". Telos, jul.-sept. 2008, n. 76, pp. 128-131.

Lehmberg, Timm; Rehm, Georg; Witt, Andreas; Zimmermann, Felix. "Digital text collections, linguistic research data, and mashups: notes on the legal situation". Library trends, 2008, v. 57, n. 1 , pp. 52-71.

López-de-Quintana, Eugenio. “Transición y tendencias de la documentación en televisión: digitalización y nuevo mercado audiovisual". El profesional de la información, 2007, sept.-oct., v.16, n. 5, pp. 397-408

http://www.elprofesionaldelainformacion.com/ contenidos/2007/septiembre/01.pdf

Lusoli, Wainer; Miltgen, Caroline. "Young people and emerging digital services. An explanatory survey on motivation, perception and acceptance of risks". Joint Research Center-Institute for Prospective Technologies Studies. European Commission, Luxemburg, 2009. http://ftp.jrc.es/EURdoc/JRC50089.pdf

Ofcom. Social networking. A quantitative and qualitative research report into attitudes, behaviours and use. 2 April 2008.

http://www.ofcom.org.uk/advice/media literacy/ medlitpub/medlitpubrss/socialnetworking/

Rodan, Debbie; Balnaves, Mark. "Democracy to come: active forums as indicator suites for eparticipation and e-governance". In: Electronic participation, Lecture notes in computer science, vol. 5694. Heidelberg, Berlin: Springer, 2009, pp. $175-185$.

Sæbø, Øystein; Rose, Jeremy; Nyvang, Tom. "The role of social networking services in e-participation". In: Electronic participation, Lecture notes in computer science, vol. 5694. Heidelberg, Berlin: Springer, 2009, pp. 46-55.

Saiz-García, Concepción. Obras audiovisuales y derechos de autor. Navarra: Aranzadi, 2002.

San-Millán, Elvira; Medrano, María-Luisa; Blanco, Francisco. "Social media marketing, redes sociales y metaversos". Universidad, sociedad y mercados globales. Asociación Española de Dirección y Economía de la Empresa (Aedem), 2008, pp. 353-366

Antonia Salvador-Benitez. Universidad Complutense de Madrid, Facultad de Ciencias de la Documentación.

Santísima Trinidad, 37, 28010 Madrid.

asalvador@ccinf.ucm.es

María-Estrella Gutiérrez-David. Universidad Carlos III de Madrid, Departamento de Derecho Público del Estado (Derecho Administrativo).

Madrid, 126, 28903 Getafe, Madrid.

megutier@der-pu.uc3m.es 